\title{
Above water in Q1
}

Walter Yang

Biotech stocks remain buoyant, and although funding dipped compared with the preceding two quarters, 1Q09 remained above the dire levels seen last winter. Excluding US partnership monies, the industry pulled

\section{Stock market performance}

The biotech indices were up $>11 \%$, whereas the Dow, S\&P 500 and NASDAQ were up by only $4-6 \%$.

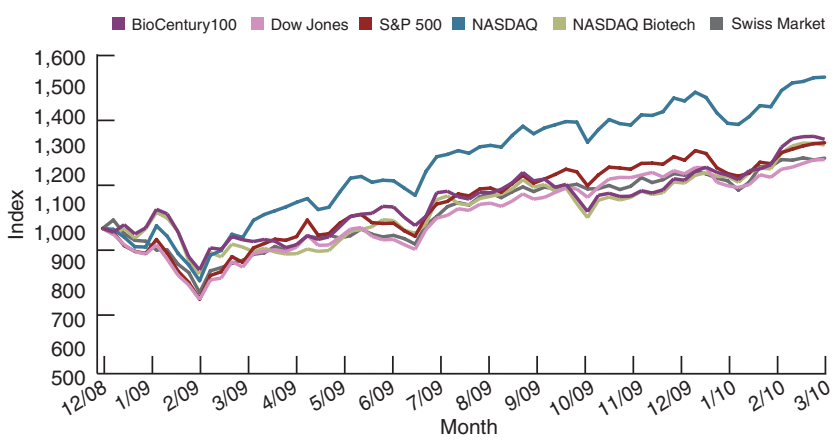

\section{Global biotech initial public offerings}

Six IPOs trickled in last quarter, raising a total of \$391.7 million.

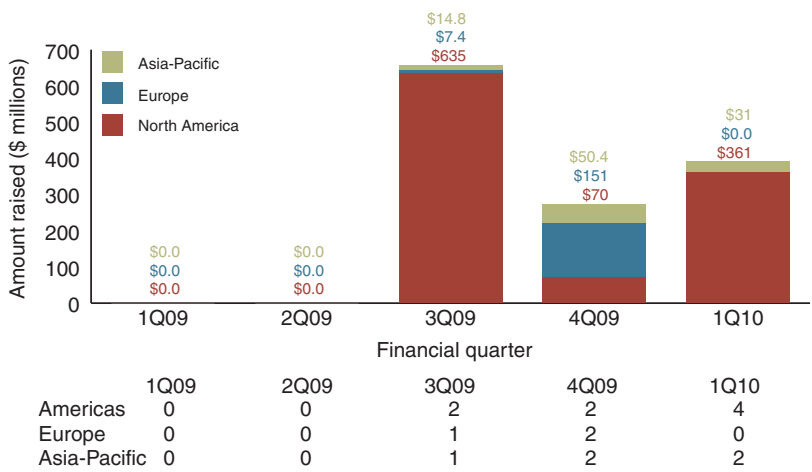

Table indicates number of IPOs. Source: BCIQ: BioCentury Online Intelligence

Notable Q1 deals

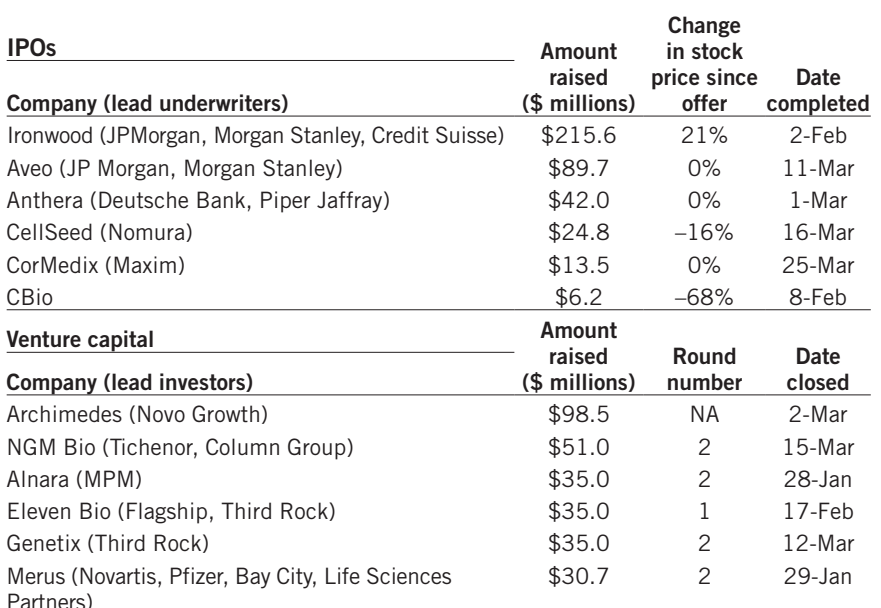

in $\$ 5.5$ billion last quarter, down 31\% from 4Q09. Six initial public offerings (IPOs) were completed, bringing funding for public floats up $45 \%$ to $\$ 391.7$ million.

\section{Global biotech industry financing}

The industry raised $\$ 11.6$ billion in $1 Q 10,49 \%$ less than in $4 Q 09$; only IPOs were up.

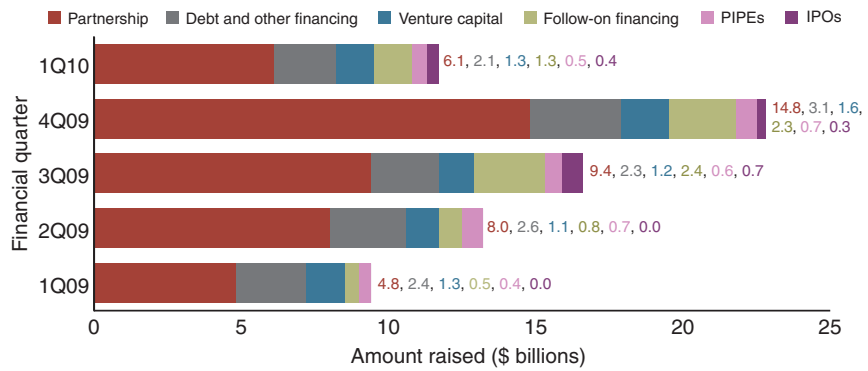

Partnership figures are for deals involving a US company. Source: BCIQ: BioCentury Online Intelligence, Burrill \& Co.

\section{Global biotech venture capital investment}

Private biotechs raised $\$ 1.3$ billion in $1 \mathrm{Q} 10$, about the same as a year ago, but down $18 \%$ from $4 Q 09$.

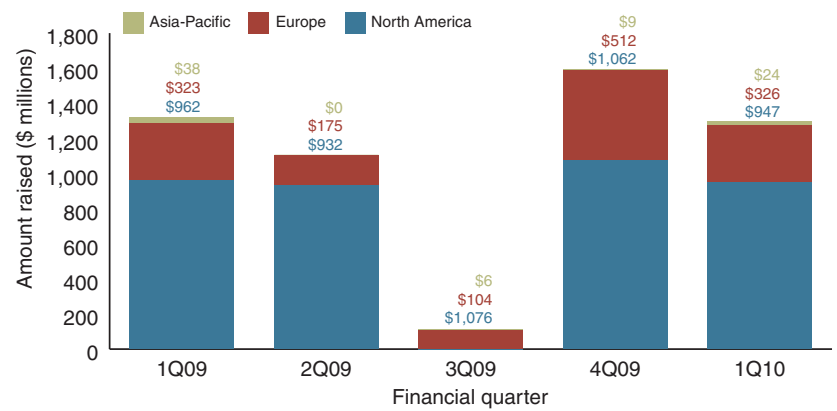

Source: $\mathrm{BCIQ}$ : BioCentury Online Intelligence

\begin{tabular}{|c|c|c|c|c|}
\hline \multicolumn{5}{|c|}{ Mergers and acquisitions } \\
\hline \multicolumn{2}{|l|}{ Target } & Acquirer & $\begin{array}{c}\text { Value } \\
(\$ \text { millions })\end{array}$ & Date announced \\
\hline \multicolumn{2}{|l|}{ Millipore } & Merck KGaA & $\$ 5,600$ & 28-Feb \\
\hline \multicolumn{2}{|c|}{ Facet Biotech } & Abbott & $\$ 722$ & 9-Mar \\
\hline \multicolumn{2}{|l|}{ Ception } & Cephalon & $\$ 250$ & 23-Feb \\
\hline \multicolumn{5}{|c|}{ Licensing/collaboration } \\
\hline Researcher & Investor & $\begin{array}{c}\text { Value } \\
\text { (\$ millions) }\end{array}$ & Deal description & \\
\hline Isis & $\begin{array}{l}\text { GlaxoSmith } \\
\text { Kline }\end{array}$ & $\$ 1,500$ & \multicolumn{2}{|c|}{$\begin{array}{l}\text { Discover and develop RNA-targeted therapeu- } \\
\text { tics for rare and infectious diseases }\end{array}$} \\
\hline Rigel & AstraZeneca & $\$ 1,300$ & \multicolumn{2}{|c|}{$\begin{array}{l}\text { Worldwide rights to develop and commercialize } \\
\text { fostamatinib (R788) }\end{array}$} \\
\hline Transgene & Novartis & $\$ 963$ & \multicolumn{2}{|c|}{$\begin{array}{l}\text { Option to obtain an exclusive, worldwide license } \\
\text { to develop and commercialize TG4010 for cancer }\end{array}$} \\
\hline Galapagos & Roche & $\$ 589$ & \multicolumn{2}{|c|}{$\begin{array}{l}\text { Discover and develop treatments for chronic } \\
\text { obstructive pulmonary disease (COPD) }\end{array}$} \\
\hline Basilea & Astellas & $\$ 514$ & \multicolumn{2}{|c|}{$\begin{array}{l}\text { Co-develop broad-spectrum, azole antifungal } \\
\text { savuconazole worldwide, excluding Japan }\end{array}$} \\
\hline
\end{tabular}

